\title{
Issues in Development
}

\section{Stem Cells: Shibboleths of Development}

\section{GRAHAM C. PARKER, MARLENE ANASTASSOVA-KRISTEVA, HAL E. BROXMEYER, WILLIAM H. DODGE, LEONARD M. EISENBERG, URSULA M. GEHLING, LOUIS M. GUENIN, RALF HUSS, NICANOR I. MOLDOVAN, MAHENDRA RAO, EDWARD F. SROUR, and MERVIN C. YODER}

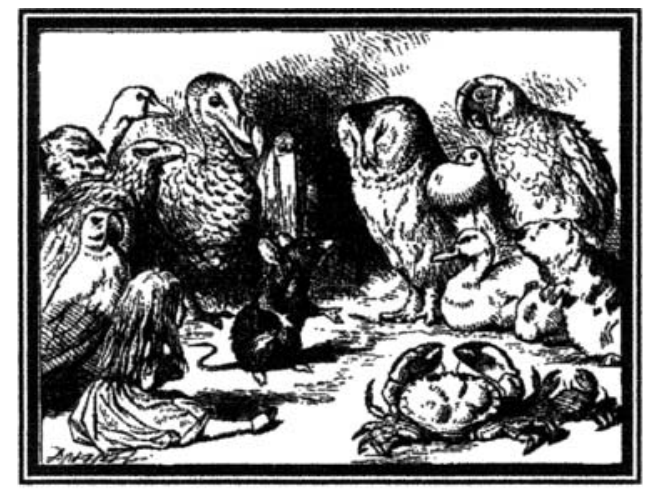

From Alice's Adventures in Wonderland, illustrated by John Tenniel.

\author{
... the Mouse replied rather crossly: \\ "Of course you know what 'it' \\ means." "I know what 'it' means well \\ enough, when I find a thing," said \\ the Duck. . . .
}

\section{-Alice's Adventures in}

Wonderland, Lewis Carroll, 1865
$\mathbf{O}$ F COURSE, neither Mouse nor Duck was referring to stem cells in their debated point that had Alice so bemused. However, as the public is continually bombarded with news and opinions concerning stem cells and whether or not the "Wonderland" of their potential is real, or only so much rhetoric, the irony is that those closest to the cutting edge share both Mouse and Duck's confidence, and contradiction, in what actually defines a stem cell.

As the fields of development and stem cell research have evolved, different concepts have emerged in these two seemingly interrelated disciplines. As a result, developmental scientists view stem cells somewhat differently than clinical scientists, who have successfully used what they characterize as stem cells for therapeutic purposes. These latter pioneers include hematologists, who by demonstrating the reconstitution of an organ system with a single multipotent cell, have an undeniably strong claim to defining the concept of what constitutes the stem cell. Prior to, and, as will become evident, following this dramatic result, hematologists and developmentalists have viewed stem cells very differently; classifying stem cells as any that led to further development and differentiation. Consequently, the vernacular and rhetoric associated with any one journal claiming an interest in stem cell research has promoted only one of these paradigms. Stem Cells and Development seeks to integrate the wealth of information the two disciplines provide and thereby close, or at least shrink, the gap between the two positions.

Hematologists have, with historically justifiable rights to make the initial definition, defined stem cells as cells that are capable of self-renewal by asymmetric division, i.e., one daughter cell is a replicate of the original; the

Editors' note: The statements and conclusions set forth in this essay do in fact reflect the editorial policy of Stem Cells and Development. Further comments should be addressed to the Editor-in-Chief (at dkenglish@msn.com) and will be published in a subsequent paper. 


\section{Asymmetric Differentiation}

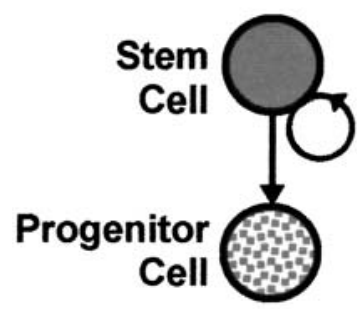

FIG. 1. Cell division producing stem cells and a progenitor cell.

other a more differentiated cell, sometimes referred to as a progenitor (Fig. 1). In this manner, the stem cell population is maintained while also providing the necessary continuous course of differentiated cells required for homeostasis and repair throughout the life of the organism.

But is the situation this simple? According to some, "stem cells" do not by necessity have to possess the capacity to self-renew to carry out their functions in homeostasis, healing, and development. Indeed, the hematopoietic system may, in fact, be somewhat unique in its requirement for a constant input of new cells derived from hematopoietic stem cells. In other tissues, this may not be the case; there, a markedly slower turnover of cells may allow for stem cell-mediated repairs and development without self-renewal. Furthermore, it is possible that in these tissues fixed stem cells are, if necessary, replaced by those recruited from marrow stores. Perhaps they are not replaced at all; when the pool is gone, the organ's functionality is nearing its end.

We asked several prominent scientists, mostly senior Editorial Board members and other select individuals, representing a variety of stem cell research interests, to address the question of what crucially defines a stem cell. What we found is a need to replace shibboleths with consensus through an agreed upon taxonomy of stem cell definition.

The research of Dr. Edward F. Srour, Professor of Medicine, Pediatrics and Microbiology/Immunology at Indiana University School of Medicine in Indianapolis, focuses on the characterization and biology of human hematopoietic stem cells (HSC). Dr. Srour reminds us that: "multiple studies have shown that transplantation of a single HSC into a lethally irradiated host is sufficient to sustain long-term reconstitution of all the blood elements of the recipient, an outcome that cannot be supported if this one stem cell did not self-renew and differentiate through most likely, asymmetric divisions. Self-renewal and multilineage differentiation are, therefore, two essential functional properties of stem cells."

Dr. Hal E. Broxmeyer, Professor of Microbiology/ Immunology and Medicine at Indiana University School of Medicine, is senior editor of the journal and a pioneer in the study of hematopoiesis in the context of normal and abnormal cell regulation and the homing/migration of hematopoietic stem and progenitor cells. Dr. Broxmeyer developed cord blood stem cell research, and set the standards for others to follow in this field. Dr. Broxmeyer makes the distinction between stem cells and the more differentiated progenitor cells: "One should not lose track of the careful distinction regarding stem and progenitor cells that has evolved over the years from the hematopoietic literature. In fact, what most nonhematopoietic investigators call stem cells very clearly fit into a progenitor cell category, and I see nothing wrong with calling these important cells 'progenitors' which give rise to differentiated progeny and, in some cases, have multipotentialities. It makes no sense to call a cell a stem cell if there is no evidence for self-renewal."

Dr. Ursula M. Gehling, of the Transplant Center of the University Hospital of Hamburg-Eppendorf, has a special interest in the developmental properties of adult human $\mathrm{CD}_{133^{+}}$stem and progenitor cells and in the characterization of various types of endothelial precursor cells: "I agree that stem cells have the ability to selfrenew, while progenitor cells cannot." However, Dr. Gehling disagrees with the National Institutes of Health (NIH) definition that says that the ability to self-renew has to be unlimited, maintaining that a limited self-renewal capacity does not exclude the possibility that a cell can be a stem cell.

Dr. Leonard M. Eisenberg, of the Medical University of South Carolina, has a special interest in stem cells that contribute to the formation and regeneration of the heart. Dr. Eisenberg argues for a broader approach in defining a stem cell: "The properties of stem cells should be examined from the end point of newly generated differentiated cells and tissue (whether in the adult or embryo), by investigating the properties and origins of the precursor cells that contribute to these events of tissue generation. In other words, stem cells should be defined solely by their potential, nothing more. However, attempts to provide a more limited definition, by predetermining the properties of stem cells (that they must have the capacity to self-renew, that they must express such-and-such cell surface markers, that must be ordered in a hierarchy according to their pluri-, multi-, and unipotentiality) does not serve science well. Instead, such limited definitions (or more accurately prejudgments) serve only to limit scientific debate, investigations, and progress. Even if hematologists are correct in prescribing the properties of HSC, should this definition of stem cells hold for the development of all tissues? After all, different tissues and differentiated cell phenotypes arose at distinct points in evolution, and it seems unlikely that the development of every tissue evolved in exactly the same manner. The reason that the study of stem cells grips our imagination is 


\section{STEM CELLS: SHIBBOLETHS OF DEVELOPMENT}

because of their potential to give rise to new or regenerated differentiated tissue. Accordingly, it is this property of stem cells that should form the basis of their definition. There have been enough reports in the literature that have demonstrated transdifferentiation of both nondifferentiated and differentiated cells, to inhibit us from prescribing a more limited definition of the cells that will provide the material for generating new and restored tissue."

In contrast, Dr. Marlene Anastassova-Kristeva, a Professor in Histology and Embryology at the Bulgarian Academy of Sciences, CSUN, UCLA, and USC, and our official consultant on classic embryology, has researched development of the reproductive and immune systems and the problems of cell differentiation and epigenesis. She is committed to the concept that the property of selfrenewal must be considered a defining feature of a stem cell: "The inner cell mass of the blastocyst is composed of pluripotent embryonic cells. That they are all pluripotent indicates that they have multiplied by symmetric division. After fertilization, an M-phase promoting factor is responsible for rapid proliferative divisions which are not combined with differentiation. This is the way liver cells and endothelial cells proliferate (1). Different tissues originate and contain their own stem cells which persist to the end of our life, the function of which is to maintain the integrity of the tissues and to keep available a steady number of stem cells, which is achieved by asymmetric division or self-renewal (2). The pluripotent embryonic cells might be named 'stem' in the broad sense of the word, but they differ from tissue-specific stem cells: The stem cells are tissue specific, partially differentiated, and committed to maintain by self-renewal the existence of the stem cell pool and by further differentiation to maintain the integrity of permanently renewing tissues. There is also cell renewal by symmetric division or simple duplication characteristic for proliferation without differentiation and self-renewal by asymmetric division characteristic only for tissue specific stem cells."

Dr. Ralf Huss, of the Institute of Pathology in Munich, has special interests in the biology of the adult stem cell niche and tissue regeneration: "I believe self-renewal might play a role in some stem cells compartments, but cannot be considered as a general rule. In the brain, astroglia seem to be a neuronal stem cell precursor with limited availability, and the same might similarly apply to the stem cell niche in the bone marrow. We are actually running out of stem cells with age, losing our ability to perform endogenous regeneration and acquire more and more degenerative processes. However, there is still a lot of room for experimental evidence to emerge."

Dr. Mahendra Rao of the National Institute on Aging, who works on adult and embryonic stem cells, also cites the brain for countering the contention that the function of stem cells is necessarily to renew tissue: "Most differentiated neural cells last the lifetime of the organism. Repair is by compensation and not by replacement. Even though stem cells have been identified in the adult, they are a miniscule population, present in a tiny part of the brain and do not appear to contribute substantially to repair. The major reparative cell in the adult brain is a blast type cell that generates support cells. These cells are either quiescent or dividing very slowly, but they can be recruited to enter the cell cycle and differentiate. They can, however, be exhausted and cannot fully repair major lesions and do not replace neurons. This might well be the case in most solid tissues, which are comprised of long-surviving cells, with some components being generally replaced by more limited progenitors that undergo exhaustion."

Dr. Rao agrees with Dr. Gehling that the capacity to self-renew is variable, not an all-or-none phenomenon: "Mesenchymal stem cells are a good example of limited versus prolonged self-renewal and limited repair versus substantial repair. They have a limited replicative capacity, age, and lack telomerase, but they divide enough and are present in enough numbers to perform most routine repairs. Depending on the definition one uses, these would or would not be stem cells."

Dr. Mervin C. Yoder, a Professor of Pediatrics, Biochemistry, and Molecular Biology at Indiana University School of Medicine, has had a long interest in developmental hematopoiesis and embryonic stem cell development. Dr. Yoder supports his fellow HSC investigators in the form of a question: "If in fact we choose to ignore selfrenewal potential as a fundamental attribute of stem cells, then how do we distinguish a progenitor cell from a stem cell?' According to Dr. Yoder, if the cell can selfrenew, it is a stem cell; if it cannot, it should be referred to as a progenitor cell. Not a bad compromise, really.

Dr. William H. Dodge, formerly of the Department of Medicine and then of the Department of Pathology of the Wake Forest University School of Medicine, is now principal owner and manager of MPrint, LLC, a company that does research in hematopoiesis. He has as a research focus residual leukemic cells and in leukemic cell quiescence. Dr. Dodge emphasizes the need for categories to avoid having to define the level of "stemness" in each situation. Dr. Dodge also discusses how the ability to selfrenew varies across cell type, as well as the issue of the state of a given cell. "The myelocyte gives rise to the neutrophil but the replicative capacity of this cell is much less that that of the progenitor, granulocyte-macrophage colony-forming cells (GM-CFC). Also, the myelocyte is never multipotent. In addition to self-renewal, most HSC are in $\mathrm{G}_{0}$, and, without a marrow stress such as chemotherapy, may remain so for the life of the individual. Are most progenitors in $\mathrm{G}_{0}$ ? Hematopoietic progenitors can not restore hematopoietic function in a myeloablated patient. HSC are different from hematopoietic progenitors in two to three ways, and hematopoietic progenitors are different from the replicating/differentiating progeny. 
"The available data show that self-renewal alone never occurs, at least not in the adult HSC. From the HSC at least, one daughter cell is still an HSC (self-renewal) and the other is differentiated out to the next stage. If both daughter cells are differentiated, then it is not an HSC. The $\mathrm{G}_{0} \mathrm{HSC}$ can be activated into the cycling state and then reverse back to the $\mathrm{G}_{0}$ state. Maintenance of the $\mathrm{G}_{0}$ cell is important from the standpoint of therapy. As we all know, after two to three chemotherapeutic regimens, the marrow can be used as an autotransplant and all blood cell lineages at their proper concentrations will be restored to the blood. However, the marrow in the recipient will have decreased numbers of long-term culture initiating cells (LTC-IC) and marrow progenitor cells as well as mesenchymal stem cells. The levels of none of these will be restored. This reflects the Hayflick hypothesis (3), and the fact that in the mouse, where it has been tested, there is a defined limit to the number of serial, marrow transplants" (4).

Dr. Rao also sees the importance of the state of a given cell in determining its identity as a stem cell: "If Peter Quesenberry is correct, then the fate of a cell depends on the stage of cell cycle at which it receives a stimulus; it is a stem or not a stem cell. It may depend on the timing. Ability to re-enter the cell cycle is a must, as is the ability to generate differentiated progeny. Within tissues, we have cells that either in vivo or in vitro are biased to making mostly cells that comprise this tissue. These cells are present in large numbers during early development and may or may not persist in the adult depending on the degree of differentiation required, the extent of regeneration seen, and so forth. At early stages, these cells undergo expansion by symmetric division without overt differentiation into phenotypes typical of that tissue. Subsequent to this expansion phase, cells undertake asymmetric division in many of the systems studied to maintain a pool of undifferentiated cells as well as to generate differentiated cells. When this phase is ending, pools of asymmetrically dividing cells may enter a reversible $\mathrm{G}_{0}$ arrest termed quiescence. Cells mature and age like other differentiated tissue cells, and so far there is no evidence of true immortality for a single stem cell other than embryonic stem (ES) cells. The data are simply not available to support the contention that stem cell populations always undergo asymmetric division and indeed examples of symmetric division abound. These tissue-specific cells do not, in general, differentiate directly into post-mitotic fully differentiated cells but instead generate what have been termed intermediate precursors or blast cells. These blast cells do not appear to undergo asymmetric division but amplify by symmetric divisions or undergo symmetric differentiation events. The lifespan of these blast/intermediates is variable and can be quite enormous, such as in the liver or T cells. Transdifferentiation, revealed competence, and plasticity are terms that define the unexpected in this hierarchical model of differentiation. Dedifferentiation is similar except that it suggests we know how the process works. In several systems, it is clear that stem cells must replicate by symmetric division. ES cell cultures and neural stem cell (NSC) cultures are good examples. Furthermore, if stemness can be attributed to a population rather than a single cell, then there is no need to invoke asymmetric division: Periodic symmetrical selfrenewing divisions followed by symmetric differentiation divisions would maintain a pool of stem cells."

Dr. Louis M. Guenin is an instructor at Harvard Medical School. In recent papers and a book in progress, he has presented what he describes as a consensus moral defense of ES cell research. Dr. Guenin is also keen to make the distinction between the properties of cells, properties he attributes to populations of cells. "It seems worthwhile to be careful to speak of a stem cell population where appropriate. No stem cell, as I understand it, is self-renewing and capable of differentiation. Self-renewal is an attribute of a population" $(5,6)$.

Dr. Rao agrees: “A population can exhibit immortality without each cell being immortal and this often means that the properties of populations may have to be considered rather than that of individual cells."

Dr. Nicanor I. Moldovan, of the Ohio State University in Columbus, is interested in the nature and plasticity of endothelial progenitor cells. In this issue, he describes their engraftment in target tissues, with emphasis on the control of this process by biophysical factors, as well as in the intercellular cooperation in angiogenesis. "Self-renewal and differentiation might be considered two different properties, overlapping in embryonic 'stem cells,' but more or less separate in their adult counterparts (bone marrow-derived or tissue stem, progenitor, or precursor cells). Differentiation seems to be driven by a local 'functional adaptive pressure,' triggered mostly, although not exclusively, by a tissue's microenvironment. To this, cells of various phenotypes and differentiation stages may respond based on the properties they already have, as well as by altering their transcriptome to fit their current 'functional niche.' If this is true, 'stemness' would remain semantically associated with proliferation, while differentiation, as well as transdifferentiation (or 'plasticity'), with 'functional adaptation.' 'Stem cells' will be defined based on their proliferative capacity, perhaps including self-renewal, but that may not be relevant for their fate, which is determined by the environment. Differentiation 'commitment' of cellular phenotypes, including the embryonic, hematopoietic, and mesenchymal or tissular stem cell may be simply the result of stability of any given transcriptome." Similar opinions have been expressed by others according to Dr. Moldovan, who cites Roeder and Loeffler (7) and Colvin et al. (8).

Dr. Rao describes her view of stem cell fates in Fig. 2 and summarizes her current position on defining stem 


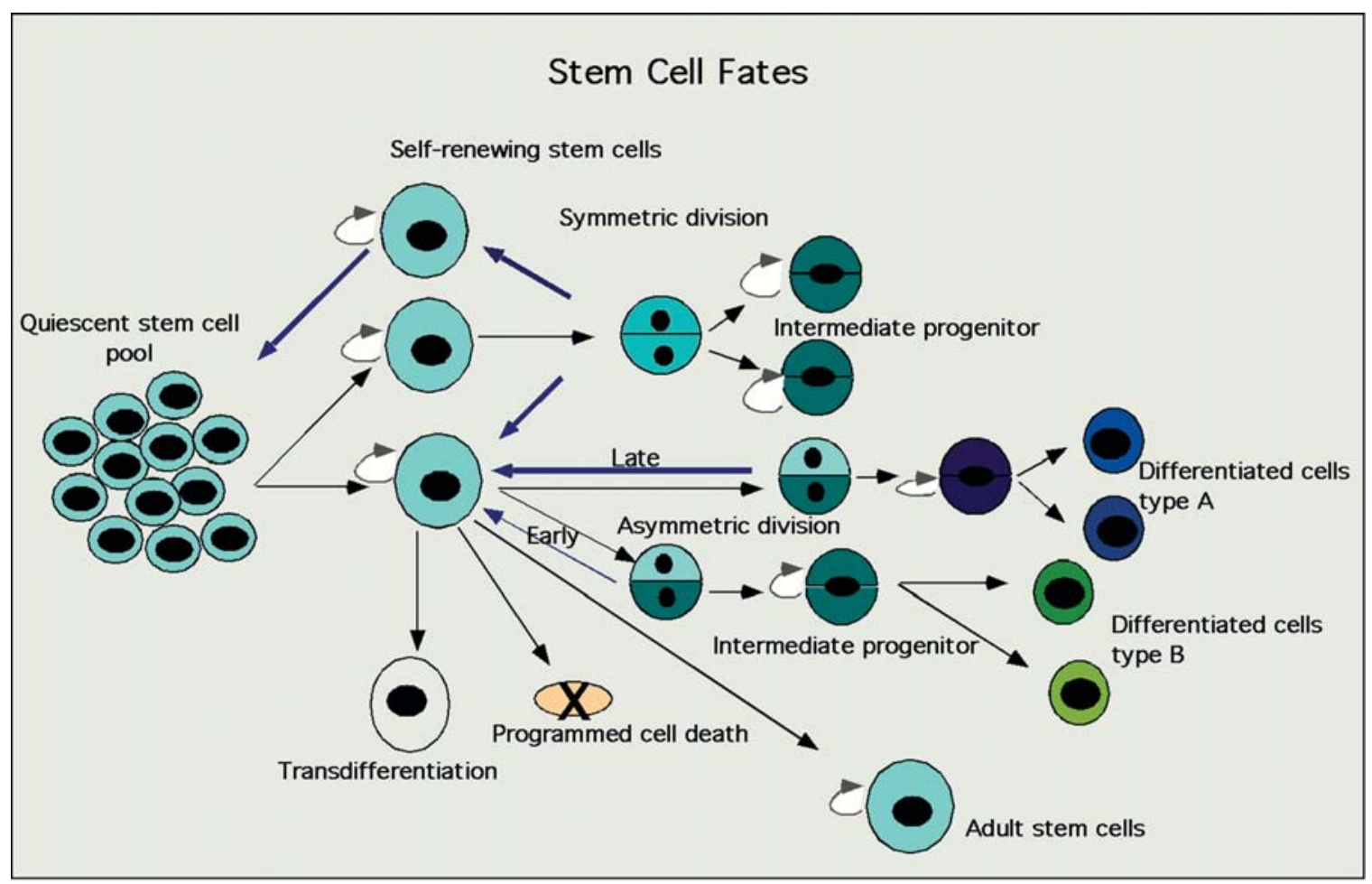

FIG. 2. Stem cell fates.

cells: "It is clear to me that some aspects of the definition must include: (i) Long-term self-renewal [yet, Dr. Rao notes, how long is open to question]; (ii) substantial contribution to a particular tissue (how much is debatable); (iii) universal stem cell markers, should they exist; (iv) some way to distinguish one tissue-specific stem cell population from that in another tissue (defining markers).

"Within this pool of stem cells in a particular tissue, one can further separate cells based on degree of self-renewal, age, state (quiescent rapidly proliferating), and so forth as long as one understands that this is a continuum in the life of a stem cell. In cancer, repair, and other situations, it becomes pretty clear that stem cells can be causative or if differentiation is affected they may be normal and accumulate simply because the feedback regulation of numbers is lost. Keloids, polyps, and precancerous tumors all fit in well as does the two-step hypothesis for cancer. Defining when one is a stem cell as opposed to a blast or intermediate progenitor is still difficult because the data as to whether blast cells all undergo symmetric division or whether all stem cells necessarily self-renew by asymmetric division are not robust."

So it appears that, for now at least, stem cells remain the shibboleths of development. There appears to be little to no consensus, even within disciplines, as to the properties that are either necessary, or indeed sufficient, for a cell to be termed a stem cell. What we can count on, however, is considerable input from both sides on which characteristics are essential for a cell to be, in fact, a stem cell. Agreement on the essential characteristics of any and all stem cells would provide an excellent start to our quest of providing a unifying definition of a stem cell. In this report, noted authorities have referred to differentiation potential, self-renewal, cell populations, cell cycle status, and cellular niche. There appears to be consensus from both hematologists and developmentalists on the latter three properties. Furthermore, almost all agree on the property of differentiation potential as being cardinal to "stemness," except for Dr. Moldovan, who turns the argument on its head by inviting us to view such fate determination as being less a property as an inevitable result of niche influence. This leaves the property of self-renewal, which remains the sine qua non of stem cells for our hematologists. Here, Dr. Rao is our heretic, by ascribing the property of self-renewal to progenitor cells, a position contrary to the dogma held by all of the other commentators invited to express an opinion.

Perhaps the only way we can all safely cross the river of Jordan is by considering, as has been mooted by a number of contributors, the property of self-renewal as a variable: A cell's ability to self-renew could then be placed along a continuum from a theoretical infinite to an observable null capacity to self-renew. Then perhaps our tribes of hematologists and developmentalists can "pronounce" the shibboleth in one tongue, and the role 


\section{PARKER ET AL.}

of stem cells in development can become defined by functional consequence rather than a single pre-existing property that may or may not play a role in that cell's fate.

\section{REFERENCES}

1. Alberts B, A Johnson, J Lewis, M Raff, D Bray, K Hopkin, K Roberts and P Walter. (1989). Molecular Biology of the Cell, $2^{\text {nd }}$ ed. Garland Publishing, New York, pp 966-970.

2. Anastassova-Kristeva M. (2003). The origin and development of the immune system with a view to stem cell therapy. J Hematother Stem Cell Res 12:137-154.

3. Hayflick L, and PS Moorehead. (1961). The serial cultivation of human diploid cell strains. Exp Cell Res 25:585-621.

4. Wolf NS, GV Priestly and LE Averill. (1983). Depletion of reserve in the hemopoietic system: III. Factors affecting the serial transplantation of bone marrow. Exp Hematol 11:762-771.
5. van der Kooy D and S Weiss. (2000). Why stem cells? Science 287:1439-1441.

6. Watt FM and BLM Hogan. (2000). Out of Eden: Stem cells and their niche. Science 287:1427-1430.

7. Roeder I and M Loeffler. (2002). A novel dynamic model of hematopoietic stem cell organization based on the concept of within-tissue plasticity. Exp Hematol 30:853-861.

8. Colvin GA, JF Lambert, BE Moore, JE Carlson, MS Dooner, M Abedi, J Cerny and PJ Quesenberry. (2004). Intrinsic stem cell/progenitor plasticity: Inversions. J Cell Physiol 199:20-31.

Address reprint requests to: Graham C. Parker, Ph.D.

Children's Research Center of Michigan Carman and Ann Adams Department of Pediatrics Wayne State University School of Medicine 3901 Beaubien Detroit, MI 48201

E-mail: gparker@med.wayne.edu 